3 Dietze R, Hadad DJ, McGee B, et al. Early and extended early bactericidal activity of linezolid in pulmonary tuberculosis. Am J Respir Crit Care Med 2008; 178: 1180-1185.

4 Louie A, Heine HS, Kim K, et al. Use of an in vitro pharmacodynamic model to derive a linezolid regimen that optimizes bacterial kill and prevents emergence of resistance in Bacillus anthracis. Antimicrob Agents Chemother 2008; 52: 2486-2496.
5 Rodriguez JC, Cebrián L, López M, et al. Mutant prevention concentration: comparison of fluoroquinolones and linezolid with Mycobacterium tuberculosis. J Antimicrob Chemother 2004; 53: 441-444.

\title{
Small airway obstruction in severe pulmonary arterial hypertension correlates with increased airway CD8+ T-cells and fractalkine expression
}

\section{To the Editors:}

Pulmonary arterial hypertension (PAH) is primarily a disease of lung small arteries. However, several studies have documented mild-to-moderate peripheral airflow obstruction in most adults [1-3] and children [4] with $\mathrm{PAH}$, which could be significantly reversed with $\beta_{2}$-agonist administration [5]. Although peribronchial infiltrates have been scarcely reported in PAH [1], it is still unclear whether airway dysfunction occurs as a result of lung vascular disease or from a direct impairment of the airways.

In lung specimens from six patients with severe group I PAH [6] undergoing lung transplantation (and who did not display signs of cardiopulmonary decompensation at that time), we assessed airway inflammatory cell infiltration and $\mathrm{PAH}-$ related chemokine expression in comparison with specimens from nine nonsmoking controls (sampled as far as possible from the tumour) and correlated findings to lung function data. Patient's characteristics and lung function tests are summarised in table 1.

No impairment of routine lung function tests was observed in PAH patients, except a trend for lower forced expiratory volume in $1 \mathrm{~s}$ and increased residual volume. However, among indices of small airway function, corrected mean maximal expiratory flow (MEF50) [2] was significantly decreased in severe $\mathrm{PAH}$ patients compared with controls (table $1 ; \mathrm{p}<0.05$ ). Highly significant increases in CD3+ T-cells were observed within the epithelium of large and small airways of PAH patients $(\mathrm{p}<0.01)$, as well as in submucosal glands and in lamina of bronchioles. CD4/CD8 immunohistochemistry indicated that these $\mathrm{T}$ lymphocytes consisted mainly of CD8+ T-cells (fig. 1). In contrast, no significant changes were observed for neutrophils and macrophages, except a modest increase of macrophages in small airways $(\mathrm{p}=0.03)$. In addition, intraepithelial infiltration of CD8+ T-cells correlated with corrected MEF50 $\left(r_{s}=-0.81, p=0.05\right)$ in small airways; a functional parameter of small airway obstruction in these patients (fig. 2). Moreover, immunoreactive cells for fractalkine were observed in small pulmonary arteries of lung sections from PAH patients, as well as in large $(p=0.003)$ and small airways $(p=0.002)$ that consisted of structural cells such as epithelial cells and subepithelial inflammatory cells, in contrast to RANTES which did not significantly differ between groups (fig. 3).

In three out of $10 \mathrm{PAH}$ patients for whom lung specimens were available, FERNANDEZ-BONETTI and LuPI [1] described the existence of airway narrowing, bronchial wall thickening and mononuclear infiltrates dominated by lymphocytes with some plasma cells, as well as a few granulocytes. Accordingly, we showed that this inflammatory infiltrate mainly consists of CD3+ T-cells and, to a marginal extent, macrophages, and that large airways are also consistently infiltrated by T-cells. Although we can not formally exclude a difference in sensitivity of CD8 versus CD4 tissue immunodetection, T-cell infiltrates seem to predominantly consist of CD8+ lymphocytes. It is tempting to speculate that fractalkine, which

\begin{tabular}{|c|c|c|}
\hline \multirow[t]{2}{*}{ TABLE 1} & \multicolumn{2}{|c|}{$\begin{array}{l}\text { Patients' characteristics with hemodynamic and } \\
\text { lung function tests }\end{array}$} \\
\hline & PAH & Controls \\
\hline Subjects $\mathrm{n}$ & 6 & 9 \\
\hline Age yrs & $45 \pm 14$ & $62 \pm 7$ \\
\hline Male:female n & $4: 2$ & $4: 5$ \\
\hline $\bar{P}$ pa $\mathrm{mmHg}$ & $73 \pm 9$ & ND \\
\hline FEV $1 \%$ pred & $81 \pm 10$ & $107 \pm 3$ \\
\hline $\mathrm{FEV}_{1} / \mathrm{VC} \%$ & $70 \pm 6$ & $76 \pm 5$ \\
\hline TLC \% pred & $98 \pm 5$ & $111 \pm 4$ \\
\hline RV \% pred & $136 \pm 31$ & $80 \pm 7$ \\
\hline MEF50 \% pred & 82 & 86 \\
\hline Corr MEF50 s $\mathrm{s}^{-1 \hbar}$ & $1.5 \pm 0.5^{*}$ & $1.9 \pm 0.2$ \\
\hline DL,CO \% pred & $80 \pm 24$ & $86 \pm 10$ \\
\hline \multicolumn{3}{|c|}{$\begin{array}{l}\text { Data are presented as mean } \pm \mathrm{SD} \text {, unless otherwise stated. PAH: pulmonary } \\
\text { arterial hypertension; } \bar{P} \text { pa: mean pulmonary artery pressure; FEV } 1 \text { : forced } \\
\text { expiratory volume in } 1 \mathrm{~s} ; \% \text { pred: \% predicted; } \mathrm{VC} \text { : vital capacity; TLC: total lung } \\
\text { capacity; RV: residual volume; MEF50: mean maximal expiratory flow; } D L, \mathrm{CO} \text { : } \\
\text { diffusing capacity of the lung for carbon monoxide; ND: not determined. } \\
\text { \#: MEF50 corrected for remaining VC fraction, corr MEF50 }=\mathrm{MEF} 50 \times(0.50 \times \mathrm{VC})^{-1} \text {. } \\
\text { *: } \mathrm{p}<0.05 \text {. }\end{array}$} \\
\hline
\end{tabular}



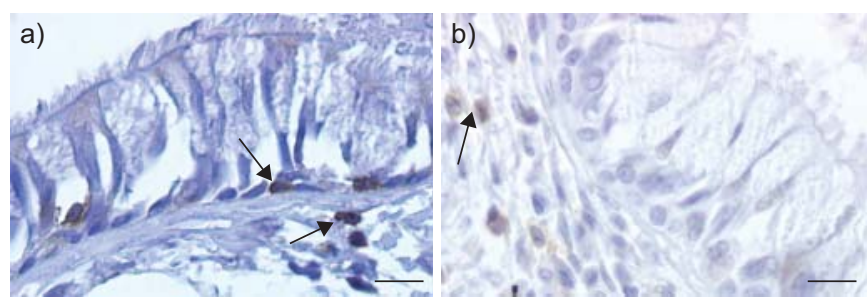

c)

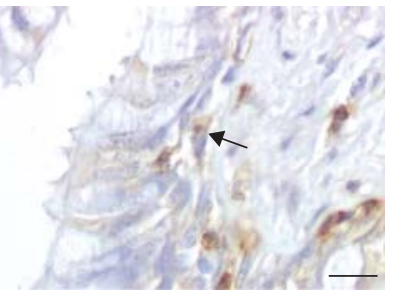

d)

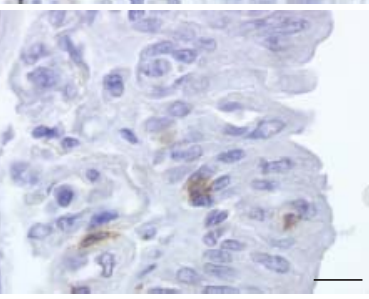

e)

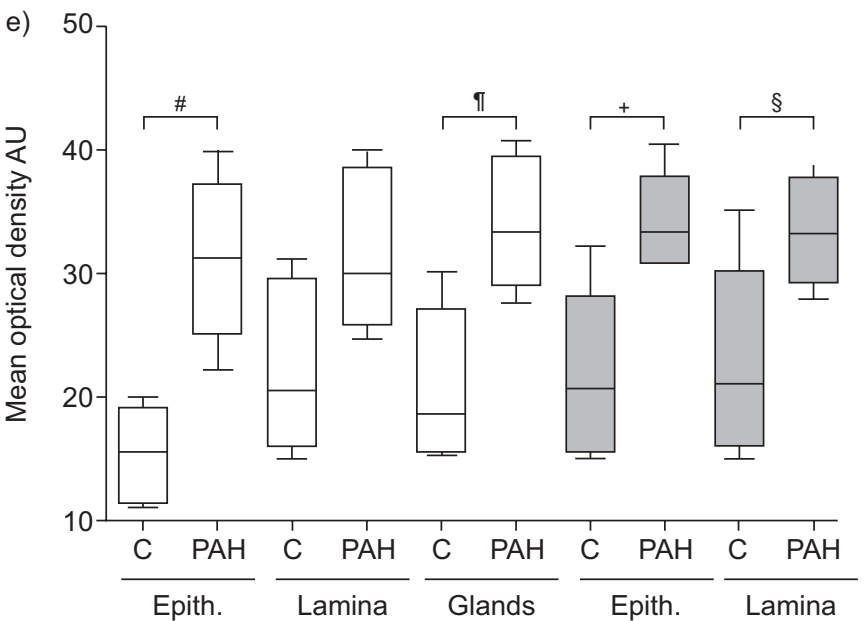

FIGURE 1. Photomicrographs of lung sections from a pulmonary arterial hypertension (PAH) patient immunostained for a) CD3, b) CD4 and c) CD8. d) CD3 expression in a control patient. Scale bars $=160 \mu \mathrm{m}$. Arrows indicate examples of stained T-cells. e) CD3+ T-cells in airway tissue from severe PAH patients versus controls $(C)$. Mean optical density of $\mathrm{CD} 3$ staining is shown in the different microcompartments of large $(\square)$ and small $(\square)$ airways, in PAH versus control patients. Horizontal bars indicate medians. Intergroup comparison performed by the Mann-Whitney U-test. AU: arbitrary units; Epith.: epithelium. ${ }^{*}: p=0.002$; ๑: $p=0.004 ;^{+}: p=0.009 ;{ }^{\text {s. }}: p=0.03$

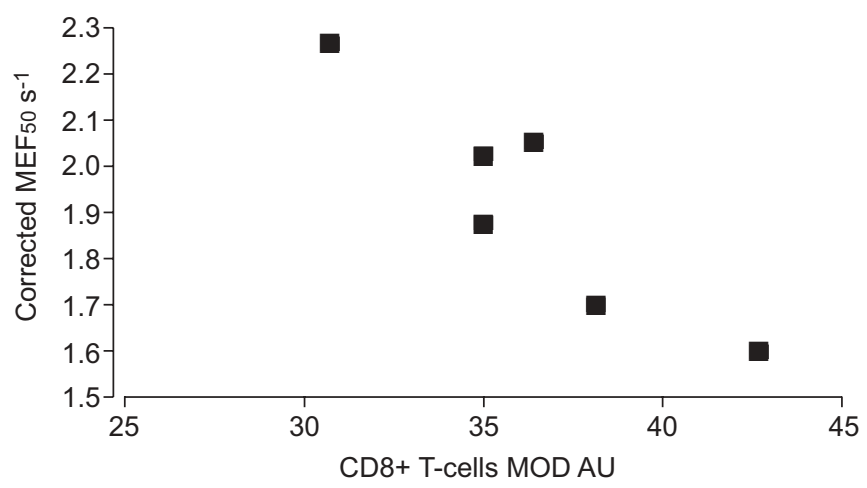

FIGURE 2. CD8+ T-cells plotted against corrected mean maximal expiratory flow (MEF50) in severe pulmonary arterial hypertension patients, and assessed by the Spearman's correlation test. MOD: mean optical density; AU: arbitrary units. $r_{s}=-0.81 ; p=0.05$.
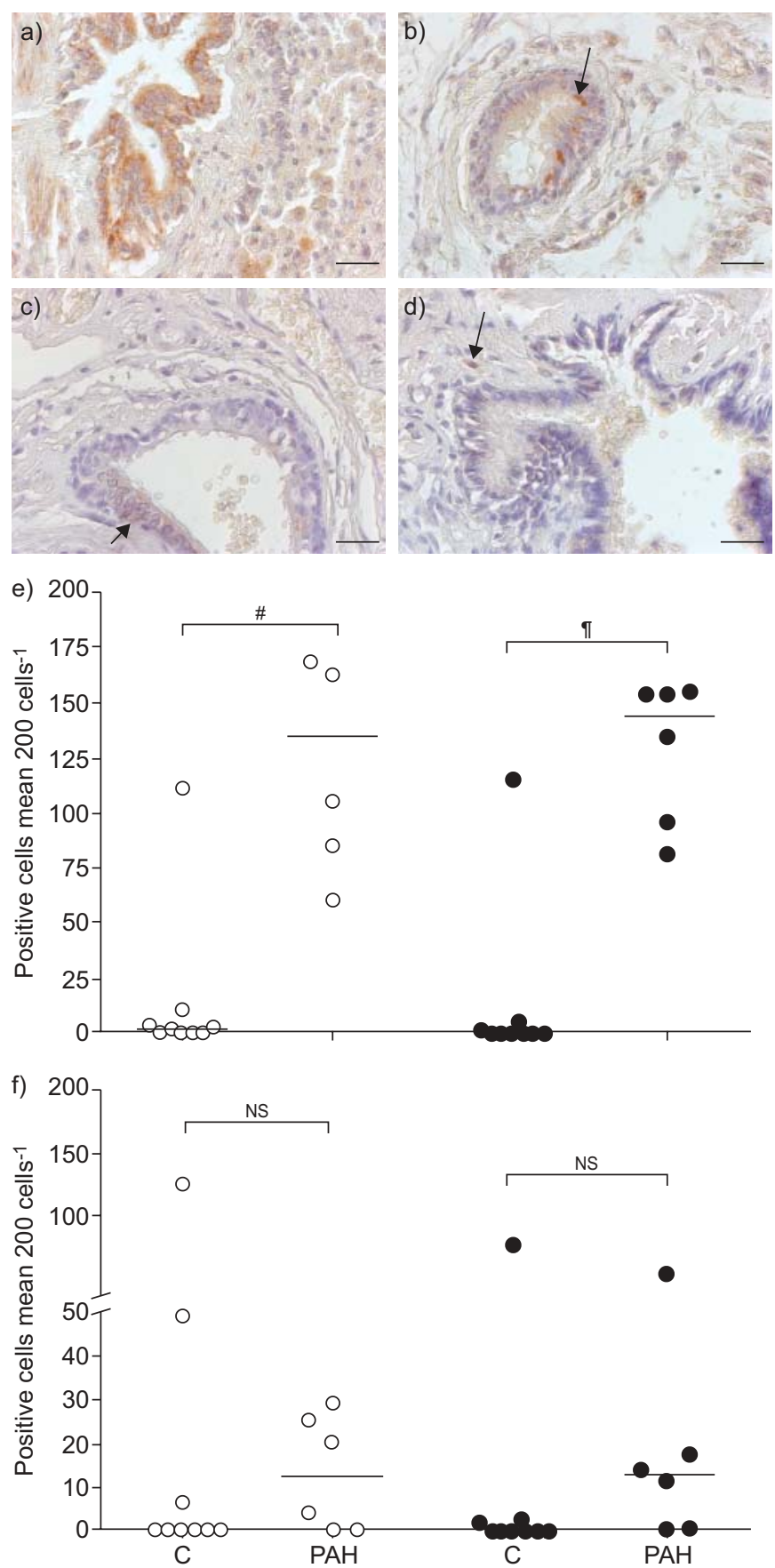

FIGURE 3. Photomicrographs from a, b) pulmonary arterial hypertension (PAH) versus c, d) control patients immunostained for fractalkine (a, c) or RANTES (b, d). The arrows indicate positive cells. Scale bars $=80 \mu \mathrm{m}$. e) Fractalkine and f) RANTES immunodetection in airway tissue from severe PAH versus control (C) patients. Intergroup comparison was performed by the Mann-Whitney U-test. $\mathrm{O}$ : large airways; • : small airways. ${ }^{\#}: p=0.003 ;{ }^{\natural}: p=0.002$; NS: nonsignificant.

appears to be increased within epithelial and subepithelial areas of the airways in our severe $\mathrm{PAH}$ patients, could trigger smooth muscle hypertrophy [7] around the airways that could account for peripheral airway obstruction and hyperresponsiveness. Airway infiltration by CD8+ T-cells has been observed in chronic obstructive pulmonary disease (COPD) 
[8], as well as in severe asthma [9] and has been related to lung function decline.

The mechanisms of airway inflammation in PAH are unknown. T-cell influx to the airways could potentially result in PAH from a spill over of chemokines, such as fractalkine or RANTES [10], in surrounding peripheral airways. However, this seems unlikely, notably because T-cells infiltrate both large and small airways. An alternative explanation is airway epithelial damage (by viruses, toxins, autoimmunity or drugs), which could occur concomitantly to the endothelial injury that primarily underlies PAH. However, we did not observe airway epithelial changes in secretory component or Clara cell protein content in these PAH patients, used as controls in our previous study of COPD patients [11].

Our data suggest that CD8+ T-cell infiltration of the airways is not only observed in typical obstructive airway diseases, such as COPD and severe asthma, but also in severe PAH. The clinical relevance of airway inflammation in PAH could include asthma-like symptoms, while $\mathrm{PAH}$ masquerading asthma has also been related to dilation of proximal bronchial vessels [12]. Future studies should confirm these findings in a larger series of $\mathrm{PAH}$ patients of varying phenotype and severity, as well as explore the molecular determinants and clinical relevance of CD8-mediated inflammatory responses in the airways.

\section{Ars*, P. Thurion ${ }^{\#}$, M. Delos", Y. Sibille* and C. Pilette*} *Unit of Pneumology, Cliniques universitaires St-Luc, Université catholique de Louvain, and "Laboratory of Pathology, Cliniques universitaires de Mont-Godinne, Université catholique de Louvain, Brussels, Belgium.

Correspondence: C. Pilette, Unit of Pneumology, Cliniques universitaires St-Luc, Université catholique de Louvain, Avenue Hippocrate 54/UCL5490, B-1200 Brussels, Belgium. E-mail: charles.pilette@uclouvain.be

Statement of Interest: None declared.
Acknowledgements: The authors would like to thank Y. Giot (Pathology Dept, Cliniques universitaires St-Luc, Université catholique de Louvain, Belgium, Brussels) for help with quantification of chemokine-expressing cells.

\section{REFERENCES}

1 Fernandez-Bonetti P, Lupi-Herrera E, Martinez-Guerra ML. Peripheral airways obstruction in idiopathic pulmonary artery hypertension (primary). Chest 1983; 83: 732-738.

2 Meyer FJ, Ewert R, Hoeper MM, et al. Peripheral airway obstruction in primary pulmonary hypertension. Thorax 2002; 57: 473-476.

3 Jing ZC, Xu XQ, Badesch DB, et al. Pulmonary function testing in patients with pulmonary arterial hypertension. Respir Med 2009; 103: $1136-1142$.

4 Rastogi D, Ngai P, Barst RJ, et al. Lower airway obstruction, bronchial hyperresponsiveness, and primary pulmonary hypertension in children. Pediatr Pulmonol 2004; 37: 50-55.

5 Spiekerkoetter E, Hoeper MM. Effect of inhaled salbutamol in primary pulmonary hypertension. Eur Respir J 2002; 20: 524-528.

6 Simonneau G, Robbins IM, Beghetti M, et al. Updated clinical classification of pulmonary hypertension. J Am Coll Cardiol 2009; 54: Suppl. 1, S43-S54.

7 Perros F, Dorfmüller P, Souza R, et al. Fractalkine-induced smooth muscle cell proliferation in pulmonary hypertension. Eur Respir $J$ 2007; 29: 937-943.

8 O'Shaughnessy TC, Ansari TW, Barnes NC, et al. Inflammation in bronchial biopsies of subjects with chronic bronchitis: inverse relationship of CD8+ T lymphocytes with FEV1. Am J Respir Crit Care Med 1997; 155: 852-857.

9 van Rensen EL, Sont JK, Evertse CE, et al. Bronchial CD8 cell infiltrate and lung function decline in asthma. Am J Respir Crit Care Med 2005; 172: 837-841.

10 Dorfmüller P, Perros F, Balabanian $\mathrm{K}$, et al. Inflammation in pulmonary arterial hypertension. Eur Respir J 2003; 22: 358-363.

11 Pilette C, Sibille Y. Reduced epithelial expression of secretory component in small airways correlates with airflow obstruction in chronic obstructive pulmonary disease. Am J Respir Crit Care Med 2001; 163: 185-194.

12 Achouh L, Montani D, Garcia G, et al. Pulmonary arterial hypertension masquerading as severe refractory asthma. Eur Respir J 2008; 32: 513-516. 